\title{
Assessment of the geomechanical state of the rock mass in the Streltsovsk ore field region according to high-precision deformation measurements
}

\author{
Vladimir Lugovoi , Igor Rasskazov, Denis Tsoi, Andrey Gladyr and Maksim Rasskazov \\ Mining Institute of the Far Eastern Branch of the Russian Academy of Sciences, 680000, 51, \\ Turgenev st., Khabarovsk, Russian Federation
}

\begin{abstract}
The paper presents a measuring set - a single-component laser strainmeter - for geodynamic monitoring within the Streltsovsk ore field. The results of experimental studies with the participation of a laser strainmeter (deformograph) are presented and the influence of external factors on the state of the massif has been estimated. The influence of distant earthquakes on the state of the mountain massif has been estimated. The features of the deformation field behavior during preparation and implementation of a rock burst have been noted. Characteristics of rock burst precursors in the low-frequency measurement region have been given.
\end{abstract}

\section{Introduction}

A high intensity of mining operations at the mines of "Priargunsky Industrial Mining and Chemical Union" (PIMCU, southern Trans-Baikal Territory) [1, 2]) led to the formation of a vast zone of technogenic disturbance of the geological environment, which was one of the reasons for the activation of geodynamic processes in the massif rocks containing the developed deposits.

Manifestations of rock pressure during mining of deep horizons of deposits occur against the background of high modern geotectonic activity of the region.

It should be noted that this tectonically active region of Southeast Transbaikalia is poorly studied, and constant monitoring of the course of seismic and deformation processes has not been carried out until recently, with the exception of some studies of the Institute of the Earth's Crust Siberian Branch of the RAS. For this territory, comprehensive studies are needed to research the geodynamic and seismic conditions, accurately assess the nature and parameters of the tectonic stress field, especially in the area of intensive mining operations $[3,4]$.

*Corresponding author: lugovoy@dst.khv.ru 


\section{Materials and methods}

As part of the creation of a multilevel system of integrated geodynamic monitoring to control the deformation field, a 50-meter laser strainmeter was installed in the vicinity of the Streltsovsk mine field and adjacent sections of the rock mass [5].

The functional diagram of a laser strainmeter is displayed in Fig. 1.

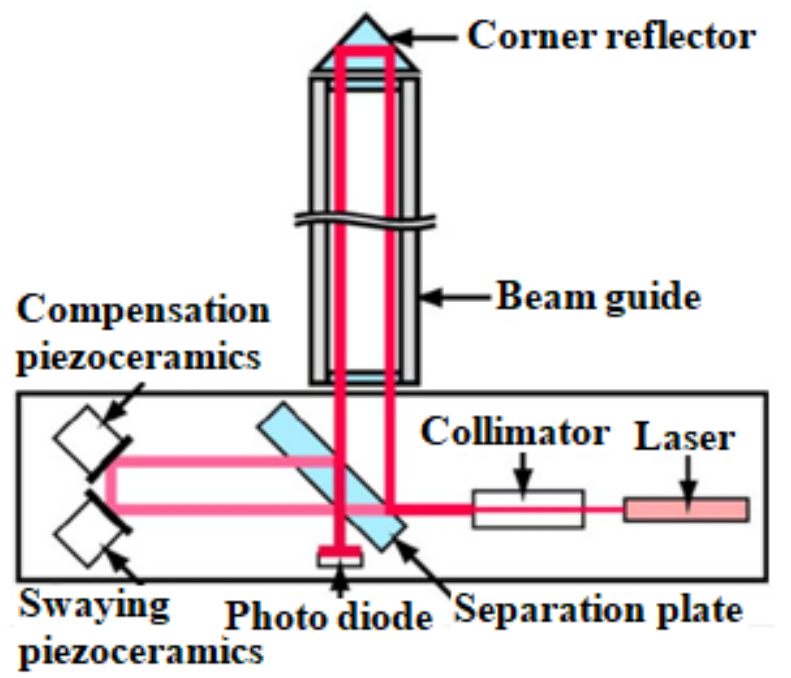

Fig. 1. Functional diagram of a laser strainmeter.

The optical part of the strainmeter is assembled on the basis of a modified Michelson interferometer of unequal-arm type with a working arm length of $50 \mathrm{~m}$, oriented to the northeast at an angle of $30^{\circ}$, and a frequency-stabilized MellesGriott laser. An interferometer is capable of detecting displacements of the Earth's crust with an accuracy of $0.1 \mathrm{~nm}$ in the frequency range from 0 to $1,000 \mathrm{~Hz}[5,13]$.

The pavilion for placing a laser strainmeter is located in an underground mine working at a depth of more than $300 \mathrm{~m}$. To ensure the necessary conditions for humidity and temperature, the pavilion is divided into two sections: a hardware section and a section for placing a beam guide. A Ballu BDH-25L dehumidifier installed in the hardware section provides a humidity level of 50-60\%. The temperature of the apparatus and light guide sections is quite stable, with a temperature variation of $\pm 2{ }^{\circ} \mathrm{C}$, which allows one to confidently work with the interference pattern.

Strainmeter's optical elements are mounted on two concrete blocks rigidly connected to the rock mass. On one of them, the optoelectronic part of the interferometer is installed, consisting of a frequency-stabilized laser, an extreme control system (registration system and a resonant amplifier), and other structural and optical elements of the laser strainmeter [12].

On another concrete block, at a distance of $50 \mathrm{~m}$ from the first one, a triple prism is installed. Between two concrete blocks, a laser beam moved through an air-filled beam guide consisting of joined pipes with an internal diameter of $0.1 \mathrm{~m}$.

The technical specifications, processing features of the measurement results, the composition and characteristics of installation in the mine working are described in detail in $[5,6]$.

In addition to the laser strainmeter, a laser nanobarograph [7] is located in the hardware section for recording atmospheric pressure variations 
The results of measurements by the strainmeter are processed using the developed "DEFORMOGRAPH" software.

Remote access available provides continuous data transfer from the strainmeter to operators in Krasnokamensk and Khabarovsk, enabling to directly control the quality of the interference pattern, the operation of the registration system, and thus to ensure continuous, long-term and stable work of the strainmeter as a whole. The created telecommunication information transmission system allows one to quickly receive and process the results of deformation measurements.

\section{Results and discussion}

Characteristic is a temporary two-week recording of the strainmeter, on which diurnal and semidiurnal tidal fluctuations (the magnitude of which is 23 hours 18 minutes and 11 hours 53 minutes, respectively) are highlighted. On this record, the origin of the periodicity of 9.3 days of a large amplitude (maximum range of about 51 microns) is of interest. The amplitude of this periodicity is almost 9 times higher than the amplitude of tidal variations. If a deformation has polarization, then the deformation registered is the projection of the disturbance's direction onto the strainmeter's optical axis. It is quite obvious that if a perturbation propagates along the optical axis of the strainmeter, then this is a true value. At other angles of propagation of the disturbance, a deformation can be significant. A feature of the recording is that the deformation at the beginning and the end of the two-week recording is at the same level, i.e. there are no shifts of the mountain massif in this section. The question of identifying this source remains open.

In temporary recordings of signals from the strainmeter, two sections are often distinguished. The first is a sharp lengthening of the base, and the second is a return to the previous level. Before this, with a sharp increase in the strainmeter's base, infra-gravity waves with a period of 3 minutes appear. In the same period, some amplification of vibrations in the region of $95 \mathrm{~Hz}$ was observed, characteristic of acoustic vibrations from explosions.

It has been established that the strainmeter confidently detects rock mass oscillations caused by blasting in mines. The experiment showed that explosive effects significantly affect the nature of the deformation field in the region of the strainmeter. The results obtained indicate that the size of the zone of strainmeter's effective control is at least $10 \mathrm{~km}$ in diameter.

Fluctuations with a period of 2-3 min, the amplitude of which varies with time, are present on almost all records by the laser strainmeter. Most likely, these fluctuations are responsible for the natural fluctuations of the mini-geoblocks of the Earth's crust located in the mine area. The cause of the fluctuations may be industrial explosions, as evidenced by concomitant fluctuations with a frequency of $95 \mathrm{~Hz}$, and other external influences. Free fluctuations of mini-blocks as a result of external influences can lead to resonance phenomena that can initiate deformation waves that provoke the dynamic destruction of highly stressed sections of the rock mass.

Fluctuations with periods of 3-7 seconds associated with wind waves that are excited in a nearby body of water and reach the laser strainmeter in the form of microseisms are recorded. In winter recordings, these signals are absent.

For a correct interpretation of the experimental data, it is important to take into account the prevailing tones and overtones of the Earth's own fluctuations [8], which are caused by numerous earthquakes at different points of the globe. According to the results of data processing, the spectrum of the Earth's own vibrations range from the main spheroidal tone ${ }_{0} \mathrm{~S}_{2}$ to another basic spheroidal tone ${ }_{0} \mathrm{~S}_{0}$, typical for the area, has been detected. 
To assess the effect of earthquakes on the state of the rock mass in the mining area at the uranium deposits of the Streltsovsk ore field, to develop methods for registering earthquakes and earthquake precursors, experimental studies were carried out with the participation of a laser strainmeter, a laser nanobarograph and a PROGNOZ ADS multichannel automated geoacoustic rock pressure monitoring system, enabling to record and identify the parameters of AE events in the frequency range $0.5-12 \mathrm{kHz}$ [9].

The studies were conducted during 2015 - 2018.

As an example, the results of the impact on the mountain massif by a large remote earthquake with a magnitude of 7.8 that occurred in Alaska Bay on January 23, 2018 at 18:31:39 local time at a distance of $5,750 \mathrm{~km}$ from the observation area are presented (Fig. 2).

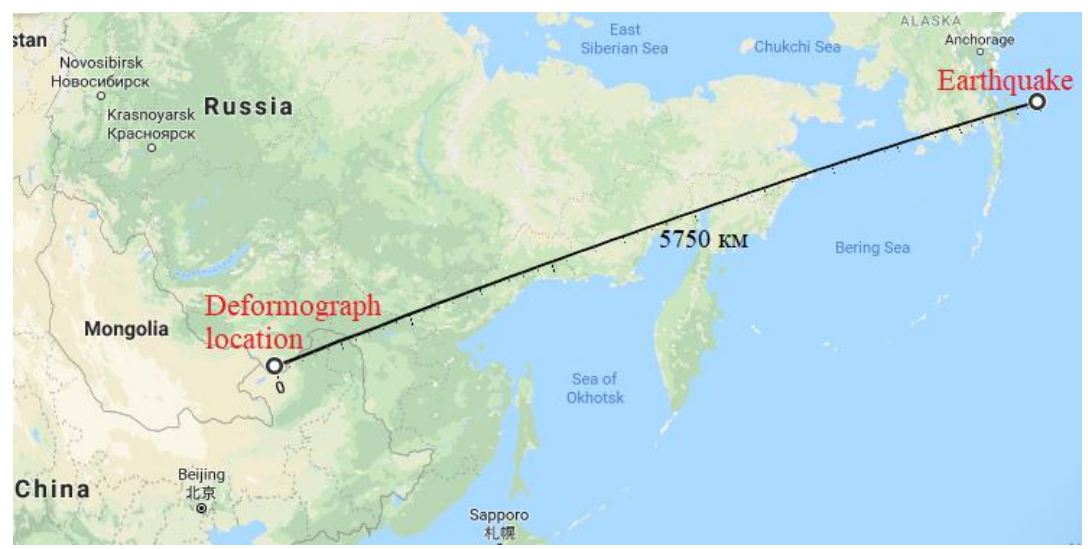

Fig. 2. The distance from the source of the earthquake (Alaska Bay) to the place of installation of the strainmeter.

Figure 3 shows a two-day recording by the laser strainmeter (one day before the earthquake and one day after). It can be seen from the figure that after the earthquake the massif experienced a relief, the relaxation time being about a day.

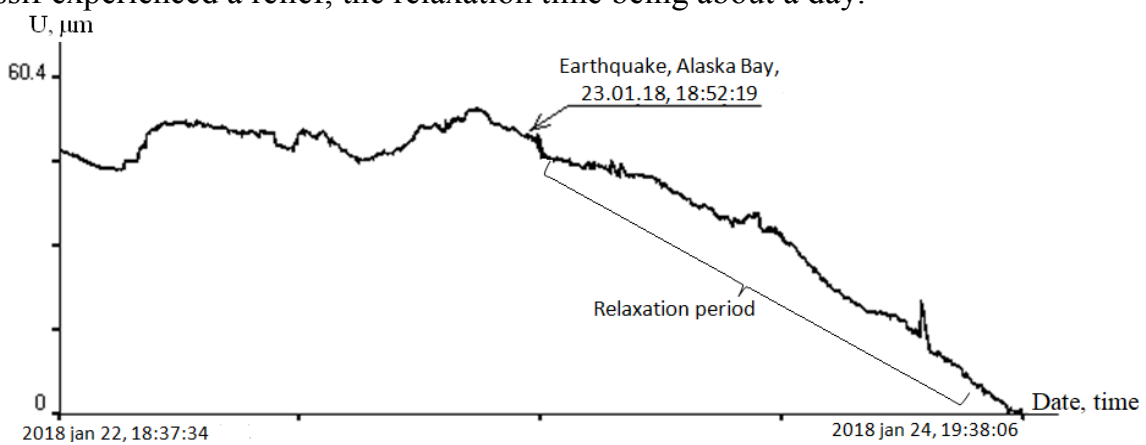

Fig. 3. Two-day recording of a laser strainmeter (a day before the earthquake and a day after).

Figure 4 shows the results of the effect of an earthquake in the low-frequency region of the strainmeter's records (decimation 10,000, frequency range analyzed up to $50 \mathrm{MHz}$ ).

It can be observed that as a result of the earthquake, there was a sharp increase in the displacement from $0.9 \mu \mathrm{m}$ to $6.1 \mu \mathrm{m}$, from the moment the seismic wave began to arrive until its influence on the massif ended within 21 minutes. 


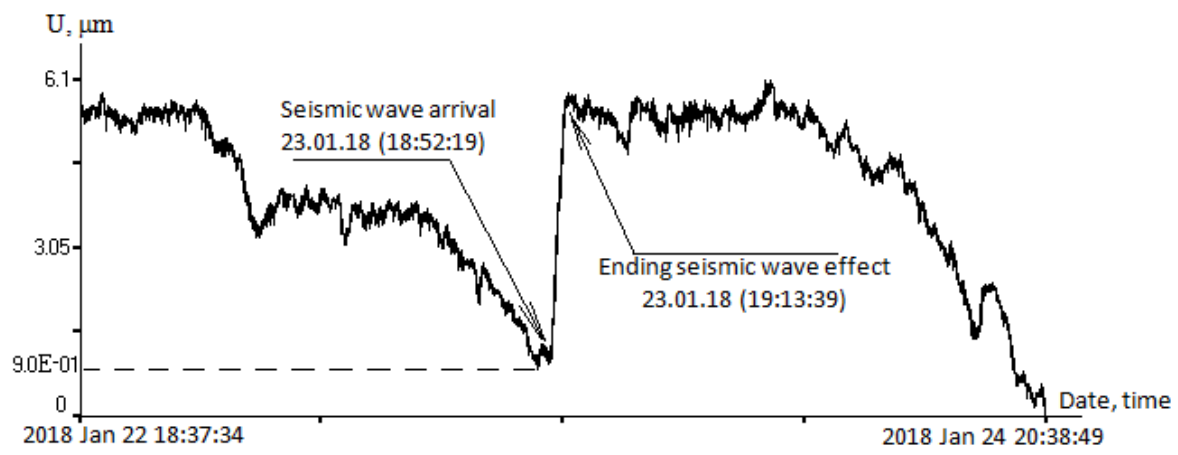

Fig. 4. The results of the effect of an earthquake in the low-frequency region (decimation $10,000)$.

The results of an analysis of the effect of distant earthquakes on the geoacoustic activity of the Streltsovsk ore field, obtained with a PROGNOZ ADS multichannel automated geoacoustic rock pressure monitoring system, are presented in Figure 5.

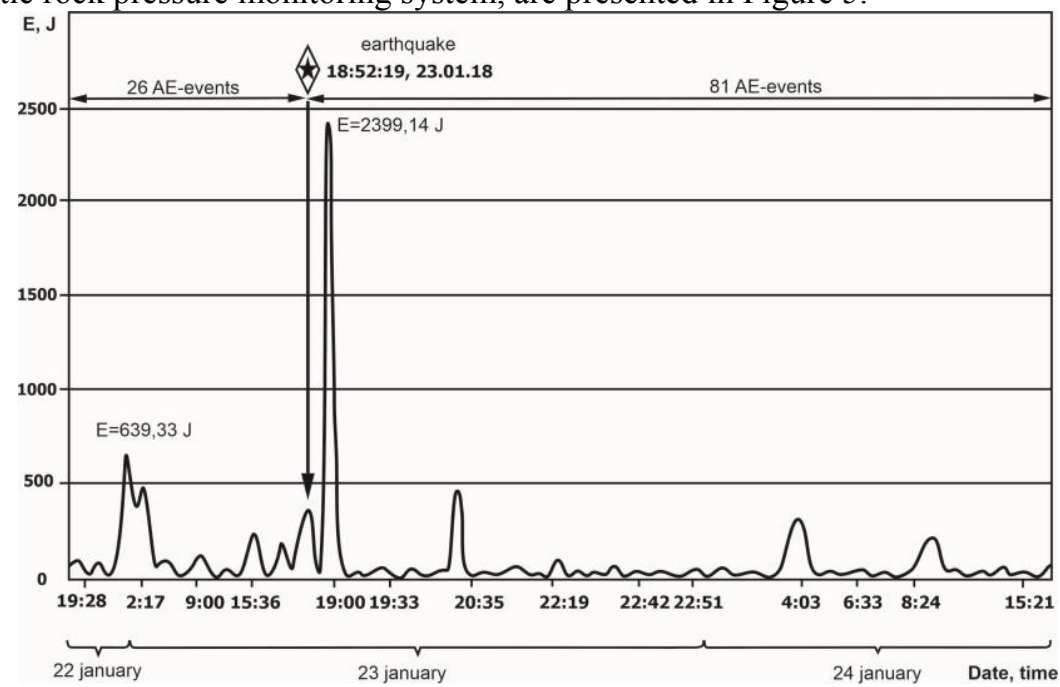

Fig. 5. Graph of geoacoustic activity before and after the earthquake.

In Figure 5, the earthquake time is indicated by a vertical arrow. The figure shows that the number of events after the earthquake increased by more than 3 times, and the energy parameter increased to values of 2,399 J.

Significant distances from earthquakes to the control zone of the massif did not allow the registration of deformation precursors of earthquakes, which could serve as an alarm signal of discontinuities in the monitored massif and which were recorded in $[10,11]$.

From the point of view of studying the possibility of registering precursors of highenergy seismic events in a rock massif, of particular interest is the analysis of deformation signals accompanying a rock burst in a zone controlled by the strainmeter recorded on February 29, 2016 (Fig. 6). 


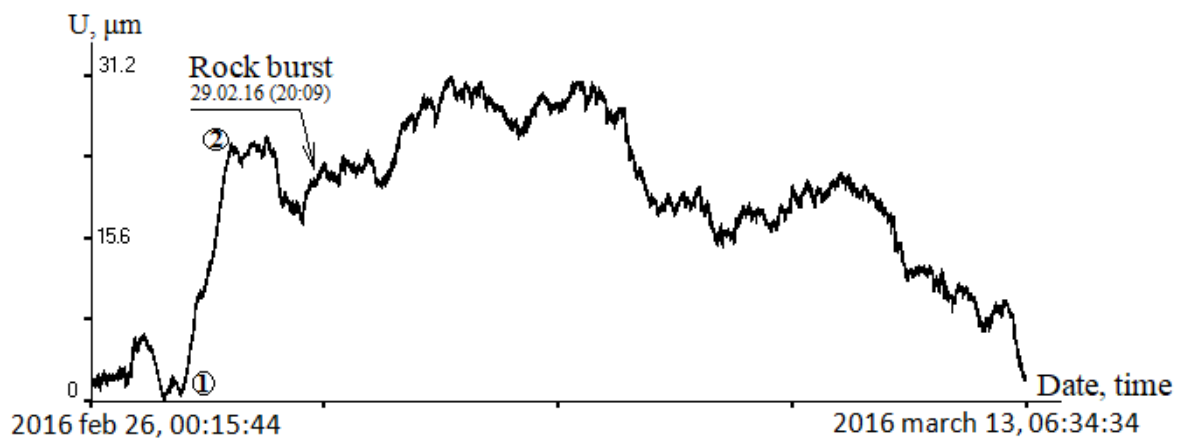

Fig. 6. Two-week recording of a laser strainmeter.

The outward manifestation of the rock burst was significant shaking of the ground surface and buildings located on the surface near the mine. Upon examination by specialists of the mine workings in the hazardous block, pinhole formation, rock outfall, rock detachment were discovered and a decision was made to lay the block down until the improvement of the geomechanical situation.

The recording of the deformation signal from a rock burst by a laser strainmeter (Fig. 6) covers the time interval from February 26 to March 13, 2016. Decimation in an analysis of the signal is of the order of 10,000 , which means the frequency range of the analysis up to $50 \mathrm{MHz}$.

An interesting section of the recording is marked by the numbers 1 and 2. It should be interpreted as a significant compression of the massif preceding the rock burst. Number 1 is the beginning of compression - February 27, 1:33 pm. Number 2 is the end of compression - February 28 7:57 pm. Thus, approximately 1.5 days before the burst, an anomalous behavior of the rock mass in the control zone of the laser strainmeter was recorded. Further, until March 13, the laser strainmeter was detecting relief of the massif and return to its original state, recorded on February 26.

Thus, observation of a deformation signal from the laser strainmeter in the lowfrequency region carries information on the preparation of a high-energy seismic event.

\section{Conclusions}

1. With the laser strainmeter for high-precision measurements of the deformation field parameters, the geomechanical state of the rock mass in the region of the Streltsovsk ore field has been assessed: diurnal and semidiurnal tidal fluctuations have been recorded, the manifestation of long-period periodicity of significant amplitude has been noted, the effect of blasting operations has been recorded, vibrations of mini-blocks located in the area of the mine, the influence of the Earth's own fluctuations have been taken into account, fluctuations connected with waves of a nearby water body have been recorded, the impact of distant earthquakes has been assessed and the behavior of the rock mass before, during and after the rock burst has been analyzed.

2. When analyzing the behavior of a rock mass in anticipation of a rock burst, in contrast to the works of the previous authors, this paper covers an anomalous behavior of the deformation field in the low-frequency region recorded by the laser strainmeter in the working range, often up to $50 \mathrm{MHz} 1.5$ days before the rock burst, which may be a harbinger of a high-energy seismic event. 


\section{References}

1. Ischukova, L. P. Uranium deposits of the Streltsovsk ore field in Transbaikalia. Irkutsk: Glazovskaya, 2007. - 260 p.

2. Rasskazov, I. Yu., Saksin, B. G., Petrov, V. A., Prosekin, B. A. Geomechanical conditions and features of dynamic manifestations of rock pressure at the Antey deposit // Physical and technical problems of mining. - 2012. - No. 3. - P. 3-13.

3. Bortnikov, N. S., Petrov, V. A., Veselovsky, A. V., Kuzmina, D. A. Leksin, A. B. Geographic information system (GIS) of the Trans-Baikal sector of the MongolOkhotsk mobile belt // Ores and Metals. - 2012. - No. 3. - P. 18 - 27.

4. Petrov, V. A., Leksin, A. B., Sankov, V. A., Pogorelov, V. V., Rasskazov, I. Yu. GISbased 3D geodynamic modelling of Transbaikalia, Russia, Int. Conf. GeoFrankfurt'2014 "Earth System Dynamics". Goethe University Frankfurt am Main. SDGG Heft 85, Abstract Volume, 2014. - P. 471.

5. Dolgikh, G. I., Rasskazov, I. Yu., Lugovoi, V. A., Anikin, P. A., Tsoi, D. I., Shvets, V. A., Yakovenko, S. V. Krasnokamensk laser strainmeter // Instruments and experimental technique. - 2013. - No. 5. - P. 138 - 139.

6. Dolgikh, G. I., Privalov, V. E. Lasers. Laser systems. - Vladivostok: Dalnauka, 2009.

7. Dolgikh, G.I., Dolgikh, S.G., Kovalev, S.N., Korenen, I.A., Novikova, OV, Ovcharenko, VV, Okuntseva, O.P. , Shvets, V.A., Chupin, V.A., Yakovenko, S.V. Laser nanobarograph and its application in the study of barodeformation interaction // Physics of the Earth. 2004. - No. 8 - P. 82-90.

8. Dolgikh, G. I., Kopville, U. Kh., Pavlov, A. N. Observation of periods of natural oscillations of the Earth by a laser strainmeter // Bulletin of the USSR Academy of Sciences. Physics of the Earth. - 1983. - No. 2. - P. 15 - 20.

9. Gladyr, A. V., Miroshnikov, V. I., Bolotin, Yu. I., et al. Technical equipment of the new generation microseismic monitoring system // Mining Informational and Analytical Bulletin. - 2012. - No. 5. - P. 174 - 180.

10. Oparin, V. N. et al. Methods and systems of seismic deformation monitoring of technogenic earthquakes and mountain bursts. Vol. 1, 2. - Novosibirsk: Publishing House of Siberian branch of the RAS, 2009.

11. Larionov, I.A., Shevtsov, B.M. Geoacoustic emission and deformation of sedimentary rocks. Problems of integrated geophysical monitoring of the Russian Far East, Petropavlovsk-Kamchatsky, October 11-17, 2009.

12. Rasskazov, I. Y., Dolgikh, G. I., Petrov, V. A., Lugovoy, V. A., Dolgikh, S. G., Saksin, B. G., Tsoi, D. I.: Use of a laser deformograph in a complex system geodynamic monitoring in the area of "Streltsovskoe" ore field. Journal of Mining Science. 6, 29-37 (2016).

13. Takemoto Shuzo, Momose Hideo, Araya Akito et al. A $100 \mathrm{~m}$ laser strainmeter system in the Kamioka Mine, Japan, for precise observations of tidal strains, Journal of Geodynamics, 2006, Vol. 41. - P. $23-29$. 